\title{
KARAYOLU ÖLÇMELERİNDE İNSANSIZ HAVA ARAÇLARININ KULLANILMASI: OKURCALAR ŞEHİR MERKEZİ ÖRNEĞİ
}

\author{
Emre TERCAN (ORCID: 0000-0001-6309-1083)* \\ Karayolları 13. Bölge Müdürlü̆ü̈, Etüt Proje ve Çevre Başmühendisliği, Antalya, Türkiye
}

Geliş / Received: 25.05 .2017 Kabul / Accepted: 08.09.2017

\begin{abstract}
ÖZ
Trafik akışının yoğun ve ölçülecek detayların fazla olduğu karayolu şehir merkezi geçişlerinde yersel yöntemlerle sayısal arazi modeli üretimi, zaman ve maliyet açısından olumsuzluk getirmektedir. Farklı becerilere sahip ölçüm araçlarını taşıyabilen ve maliyetleri düşüş eğiliminde olan insansız hava araçları (IHHA), ortofoto ve sayısal arazi modeli üretimi için etkili sistemlerdir. Bu çalışmada, GNSS-IMU destekli bir İHA ve Structure From Motion (SFM) algoritması kullanılarak 700 metrelik karayolu koridorunun 4,9 cm mekânsal çözünürlüklü ortofoto görüntüsü ve nokta bulutu elde edilmiştir. Elde edilen nokta bulutuna Cloth Simulation Filtering (CSF) ve Gaussian filtreleme yöntemleri uygulandıktan sonra test karayolu koridorunun sayısal arazi modeli elde edilmiştir. İHA sisteminin doğruluğu yersel yöntem ile test edilmiş, İHA yönteminin sert satıhlı zeminlerde 3,96 $\mathrm{cm}$, toprak zeminlerde 7,32 $\mathrm{cm}$ düşey doğrulukla 3B veri üretebileceği belirlenmiştir. Elde edilen sonuçlar, İHA sistemlerinin fotogrametrik ölçümlere engel bir detay içermeyen düz arazi yapılı karayolu koridorlarında ortofoto görüntü ve sayısal arazi modeli üretiminde oldukça etkili olduğunu göstermektedir.
\end{abstract}

Anahtar Kelimeler: İHA fotogrametrisi, sayısal arazi modeli, filtreleme, karayolu ölçmeleri, şehir geçişi

\section{USE OF UNMANNED AERIAL VEHICLES IN ROADWAY MEASUREMENTS: OKURCALAR CITY CENTER EXAMPLE}

\begin{abstract}
In the roadway city center transitions where the traffic flow is dense and the detail to be measured is high, production of digital terrain model by terrestrial methods brings negation in terms of time and cost. Unmanned aerial vehicles (UAVs), which can carry measuring instruments with different skills and tend to decrease in cost, are effective systems for production of orthophoto and digital terrain model. In this study, point cloud and 4.9 $\mathrm{cm}$ spatial resolution orthophoto image of 700-meter roadway corridor was produced by using Structure From Motion (SFM) algorithm and an UAV supported by GNSS-IMU. After applying the Cloth Simulation Filtering (CSF) and Gaussian filtering methods to the obtained point cloud, the digital terrain model of the test roadway corridor was obtained. The accuracy of the UAV system was tested by the terrestrial method, it has been determined that UAV method can obtain 3D data with a vertical accuracy of $3.96 \mathrm{~cm}$ on hard surface grounds and $7.32 \mathrm{~cm}$ on soil grounds. The results show that the UAV systems is very effective in the production of orthophoto images and digital terrain models in roadway corridors which have flatness terrain and have no objects that prevent photogrammetric surveys.
\end{abstract}

Keywords: UAV photogrammetry, digital terrain model, filtering, roadway measurements, city transition

\footnotetext{
"Corresponding author / Sorumlu yazar. Tel.: +90 24232070 00; e-mail / e-posta: etercan87@ gmail.com
} 


\section{E. TERCAN}

\section{GİRIŞ}

Fotogrametri yöntemi hava fotoğrafçılığının sonucu olarak askeri amaçlarla ortaya çıkmıştır. Geleneksel yersel ölçme yöntemlerine göre oldukça hızlı ve hassas veri elde edebilen fotogrametri, günümüzde askeri ve sivil uygulamaların yanı sıra birçok farklı alanda kullanım olanağına kavuşmuştur. Fotogrametride harita üretim amacıyla, yüksek irtifa uçakları ve yüksek çözünürlüğe sahip kameralar kullanılarak geniş ölçüm sahalarında veri toplanmaktadır [1]. GPS alıcıları, mikro işlemciler, jiroskoplar, kamera sistemleri, küçük ölçekli sensör ve elektronik iletişim ekipmanlarının maliyetlerinin düşmesi ile uzaktan kumanda edilebilen insansız hava araçlarının kullanımı artmaya başlamıştır. Sivil uygulama alanlarında çok sayıda kullanıcı için maliyet ve zaman rekabetçi alternatifler sunan ve satın alma bedelleri düşüş eğiliminde olan İHA fotogrametri sistemleri ile oldukça düşük maliyetli yüksek konumsal ve zamansal çözünürlüğe sahip 3B veri elde edilmektedir [1,2].

Ülkemizde karayolu ölçmelerinde sayısal arazi modeli ve sayısal harita üretiminde, genellikle işçilik yoğunluklu geleneksel yersel yöntemler ya da klasik hava fotogrametrisi kullanılmaktadır. Geleneksel yersel yöntemler topografya, trafik akışı ve hava koşullarındaki olumsuzluklara bağlı olarak zaman kaybına ve yüksek maliyete yol açmaktadır. Klasik hava fotogrametri sistemleri çok geniş olmayan detay alımında, zaman-maliyet dengesinde olumsuzluklara sahiptir ve kısmen yüksek ölçü hataları içermektedir. Özellikle yoğun trafiğe sahip, çok fazla detay içeren (bina, tesis, aydınlatma direği, rögar gibi) karayolu şehir merkezi geçişlerinde yersel yöntemlerle arazi ölçüm çalışmaları zaman-maliyet açısından olumsuzluk yaratmakta, işçilerden kaynaklı ihmallere bağlı olarak iş güvenliğini de riske etmektedir. Bu sebeple, sayısal fotogrametrik sistemlere göre çok düşük maliyetlerle kurulabilen İHA sistemleri, karayolu ölçüm koridorlarında ciddi bir alternatif sunmaktadır.

İHA sistemleriyle toplanan 3B veri pek çok uygulama alanında yeterli doğruluk ve hassasiyet sağlamaktadır. Ancak, uçuş sürelerinin azlığı, aşırı rüzgâr şartlarına karşı dayanıksızlık, çok geniş ölçüm sahalarında elde edilen görüntü sayısının fazla olmasına bağlı olarak dengeleme sürecindeki karmaşıklık ve örtülü arazilerde düşük hassasiyet İHA sistemlerinin olumsuzlukları olarak sayılabilir.

Literatürde, İHA fotogrametrisi kullanılarak tarımsal uygulamalar [3,4], çevresel kirliliğin belirlenmesi [5], arkeolojik alanların belgelenmesi [6-8], yol mühendisliği [9-11], 3B harita üretimi ve modellemesi [12-18] gibi farklı disiplinlerde çok sayıda araştırma yürütülmektedir. Themistocleous ve ark. [8] otopilot destekli, kamera ve GNSS alıcısı ile donatılmış, paraşüt ile iniş yapabilen bir İHA sistemi kullanarak SFM algoritması ile Kıbrıs Cumhuriyeti'nde Roma Yunanistanı dönemine ait Kourion antik kentinin sayısal yüzey modelini ve ortofoto görüntüsünü üretmişlerdir. Siebert ve Teizer [11] 3B harita veri altlığını otonom ve hızlı üretebilmek için bir İHA sistemi tasarlamışlardır. İHA sistemini karayolu yapım aşamasındaki bir kazı alanında ve yüksek hızlı tren yapım sürecinde test etmişlerdir. Üretilen sonuçlar yol yapım çalışmaları esnasında İHA sistemlerinin yersel yöntemlere ciddi bir alternatif olabileceğini göstermektedir. Hudzietz ve Saripalli [14] bir İHA sistemi ile elde edilen görüntülerden SFM algoritmasını kullanarak hassas ve etkili 3B arazi modeli üretmişlerdir.

Bu çalışmada amaç; İHA sistemi kullanılarak ortofoto görüntü ve sayısal arazi modeli üretiminin karayolu ölçüm koridorlarında uygulanabilirliğinin araştırılmasıdır. Bu çalışma ile karayolu ölçüm uygulamalarında gerçekçi ve yol mühendisliği açısından bir değerlendirme yapılması ve karayolu şehir geçişi gibi ölçüm koridorlarında İHA sistemi ile ortofoto görüntü ve sayısal arazi modeli üretiminin yüksek doğruluk ve hassasiyette yapılması, gelecekte yapılacak çalışmalara önemli bir zemin oluşturacaktır.

\section{MATERYAL VE METOT}

\subsection{Materyal}

Bu çalışmada, Antalya-Manavgat-Alanya Devlet Yolu'nda Okurcalar-İncekum mahalleleri arasında 700 metrelik bir kesim çalışma alanı olarak seçilmiştir (Şekil 1). Seçilen çalışma koridoru topografik olarak düz arazi yapısına, çok az bitki örtüsüne ve bitümlü sıcak karışım (BSK) yol kaplamasına sahiptir. Çalışma koridoru, özellikle turizm sezonunda yoğun yaya ve araç trafik akışının olduğu, araçların yüksek hızla geçiş yaptı̆̆g, trafik kazalarının sıklıkla meydana geldiği transit karayolu arterinde bulunmaktadır.

Ortofoto görüntünün, nokta bulutunun ve sayısal arazi modelinin üretilmesi için Mavinci Sirius Pro marka otonom insansız hava aracı kullanılmıştır (Şekil 2). Mavinci Sirius Pro, $163 \mathrm{~cm}$ kanat açıklıklı, $120 \mathrm{~cm}$ uzunluğunda, kamera ile ağırlığı $2,7 \mathrm{~kg}$, maksimum 50 dakika uçuş yapabilen, karakteristik düz uçuş sürati 65 $\mathrm{km} / \mathrm{sa}$ olan elapor köpükten yapılmış GPS-IMU ve otopilot destekli bir insansız hava aracıdır. İHA sisteminde GNSS RTK (gerçek zamanlı kinematik) ölçüm doğruluğu yatayda $10 \mathrm{~mm}+1,0 \mathrm{ppm}$, düşeyde $15 \mathrm{~mm}+1,0$ ppm'dir. Görüntülerin çekilmesi ve kayda alınması amacıyla $16 \mathrm{mp}$ çözünürlüklü, APS-C CMOS sensörlü, XF 18 mm f/2 R lense sahip Fuji X-M1 marka kamera kullanılmıştır (Şekil 3) [19]. 


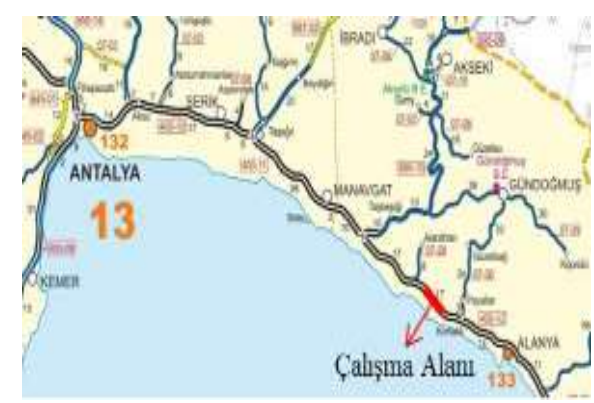

Şekil 1. Çalışma yapılan karayolu koridoru
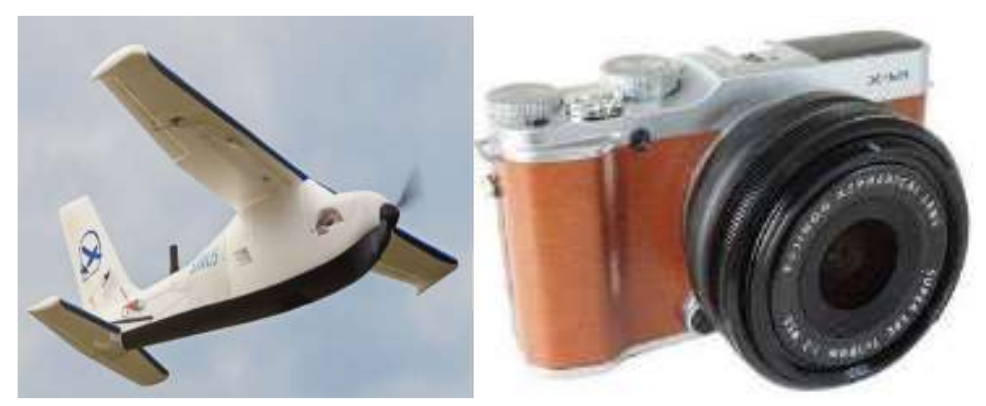

Şekil 2. Mavinci Sirius Pro İHA Şekil 3. Fuji X-M1 kamera [19] sistemi [19]

Yer kontrol noktalarının konumlarının belirlenmesi için, RTK ölçüm doğruluğu yatayda $10 \mathrm{~mm}+1,0 \mathrm{ppm}$, düşeyde $15 \mathrm{~mm}+1,0 \mathrm{ppm}$ olan Topcon Hyper V GNSS cihazı, yer kontrol noktalarının yüksekliklerinin belirlenmesi için geometrik nivelman ölçümlerinde $0,2 \mathrm{~mm}$ ölçüm hassasiyetli Topcon DL-500 elektronik dijital nivo kullanılmıştır. Çalışma alanında, İHA fotogrametri yönteminin doğruluğunu test etmek için kullanılan yersel yöntem ile ölçüm çalışmalarında, reflektörlü ölçüm hassasiyeti $1,5 \mathrm{~mm}+2$ ppm reflektörsüz ölçüm hassasiyeti 2,0 mm+2 ppm olan Leica FlexLine TS09 plus lazerli total station cihazı kullanılmıştır.

\subsection{Metot}

\subsubsection{Uçuş Planlaması ve Veri Setinin Toplanması}

Kamera özellikleri, uçuş yüksekliği, uçuş hızı ve örtüşme oranları gibi bilgilerin tanımlandığı fotogrametrik uçuş planlaması ve simülasyon işlemleri Mavinci Desktop yazılımı ile yapılmıştır. Uçuş yüksekliği 140 metre, boyuna örtüşme oranı $\% 85$, enine örtüşme oran1 \%65 olarak belirlenmiştir. Uçuş süresince test karayolu koridorunun 184 adet yüksek çözünürlüklü görüntüsü elde edilmiştir.

Blok dengeleme işleminin yapılması sürecinde ve yersel detay alım çalışmalarında kullanılmak üzere yer kontrol noktaları çalışma alanına dağıtılmıştır. Uçuş bölgesinde georeferanslama ve doğruluk kontrolü için 7 adet yer kontrol noktası tesis edilmiştir. Yer kontrol noktalarının konumları, Topcon Hyper V GNSS cihazıyla Cors-RTK yöntemiyle belirlenmiştir. Yer kontrol noktalarının yüksekliklerinin belirlenmesi için geometrik nivelman ölçümlerinde Topcon DL-500 elektronik dijital nivo kullanılmıştır. Yer kontrol noktalarının (ITRF 96 datumu-3 derece) koordinatları Tablo 1'de verilmiştir.

Tablo 1. Yer kontrol noktalarının koordinatları

\begin{tabular}{|c|c|c|c|}
\hline \multirow{2}{*}{$\begin{array}{c}\text { Nokta } \\
\text { No }\end{array}$} & \multicolumn{2}{|c|}{$\begin{array}{c}\text { Konum Değerleri } \\
\text { Epok: 2005 Datum: } \\
\text { ITRF 96 Elipsoid: GRS } \\
\mathbf{1 9 8 0}\end{array}$} & $\begin{array}{c}\text { Ortometrik } \\
\text { Yükseklik }\end{array}$ \\
\cline { 2 - 4 } & $\mathbf{y}$ & $\mathbf{x}$ & $\mathbf{H}$ \\
\hline P.1 & 384310,33 & 4057720,69 & 14,21 \\
\hline P.2 & 384418,82 & 4057721,60 & 15,72 \\
\hline P.3 & 384530,42 & 4057768,66 & 14,40 \\
\hline P.4 & 384627,99 & 4057735,70 & 11,89 \\
\hline P.5 & 384745,60 & 4057723,01 & 16,97 \\
\hline P.6 & 384821,03 & 4057699,28 & 17,34 \\
\hline P.7 & 384925,09 & 4057680,19 & 18,27 \\
\hline
\end{tabular}

\subsubsection{Fotogrametrik Veri İşleme}

Geo-referanslandırılmış 3B nokta bulutu üretmek için fotogrametrik veri işlemek gerekmektedir. Fotogrametrik yöntemler 3 boyutlu bilginin geriçatımı için iki boyutlu görüntü setlerinden faydalanmakta olup 


\section{E. TERCAN}

kamera kalibrasyon parametreleri olan iç (odak uzaklığı, ana nokta konumu, distorsiyon) parametreleri ve dış (kamera konum ve oryantasyon) parametrelere gereksinim duymaktadır [20].

Literatürde, fotoğraf imgelerinden 3B nokta bulutlarının üretimi için Lowe [21] ve Snavely ve ark. [22] SIFT (Scale Invariant Feature Transform) yöntemini kullanmışlardır. Furukawa ve ark. [23] büyük veri setleri için multi-stereo view yaklaşımını önermişlerdir. Furukawa ve Ponce [24] referanslandırılmış 3B nokta bulutlarını üretmek için birbirine komşu görüntülerin bindirilmiş alanlarında dikdörtgen biçimli parçaların hesaplanmasına dayanan bir algoritma sunmuşlardır [11]. Bu çalışmada kullanılan SFM algoritması, 3 boyutlu geri çatım için gerekli kamera kalibrasyon parametrelerini bilgisayarlı görme disiplininde geliştirilen algoritmalar aracılığıyla doğrudan birbiri ile örtüşen görüntülerden hesaplamaktadır. Analiz edilmek istenen sahnenin 3 boyutlu geometrisi, görüntü kayıt anındaki bakış açılarının farklılığından yararlanılarak en az iki resimde bulunan eşlenen detay noktalarıyla trigonometrik olarak çözülmektedir [1,25]. Bu işlem sonucunda lokal bir koordinat sisteminde eşleştirilebilen nokta sayısınca 3 boyutlu nokta bulutu üretilmektedir. Yer kontrol noktalarının eklenmesi ile bu nokta bulutu georeferanslandırılmakta ve optimize edilerek doğruluğu artırılmaktadır. Optimizasyon işlemi için genellikle ışın demetleri ile blok dengeleme yöntemi tercih edilmektedir. Nokta bulutuna bağlı olarak sayısal yükseklik modeli ve 3 boyutlu ağ modeli oluşturulmakta ve oluşturulan ağ modeli ile ortofoto üretimi gerçekleştirilmektedir. İHA fotogrametri yöntemine ait temel işlem adımları Şekil 4'te verilmiştir.

Çoğu SFM yöntemi Şekil 5'te verilen perspektif bir projeksiyon modelini varsaymaktadır. Burada 3 adet 3B öznitelik noktası fiziksel kamera içinde yer alacak projeksiyon merkezinden kaynaklanan perspektif 1şınlara sahip bir görüntü düzlemine yansıtılmaktadır. Koordinat sisteminin orijini geleneksel olarak projeksiyon merkezi ve optik eksen boyunca projeksiyon merkezinden görüntü düzlemine olan mesafe olan odak uzaklığı (f) olarak alınmaktadır [26].

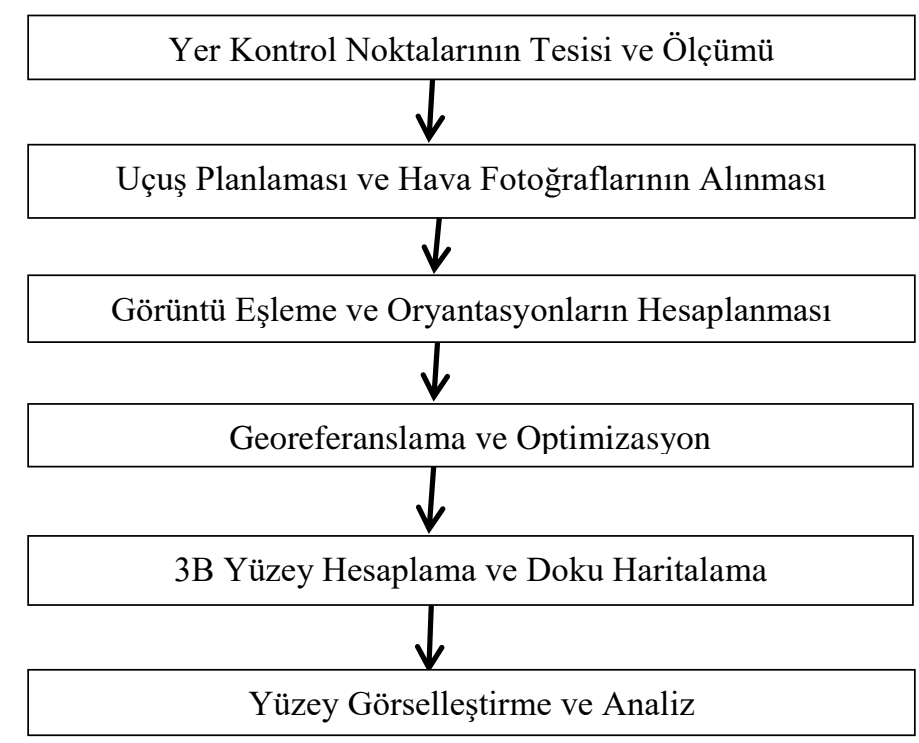

Şekil 4. İHA fotogrametrisi temel işlem adımları

Optik eksen geleneksel olarak z ekseni ile hizalanmıştır. Projeksiyon merkezinin optik eksen boyunca görüntü düzlemine izdüşümü principal point (asıl nokta) olarak adlandırılır. Thales teoreminin uygulanmasıyla, Denklem 1'deki gibi perspektif izdüşüm denklemi elde edilmektedir. Genellikle, odak uzaklığ 1 (f), ifadeyi basitleştirmek için 1 olarak ayarlanır, çünkü bu modelde f sadece görüntünün ölç̧eklenmesini değiştirir [26].

$$
\left(\begin{array}{l}
u \\
v
\end{array}\right)=\left(\begin{array}{l}
X \\
Y
\end{array}\right) \frac{f}{Z}
$$

$\mathrm{Bu}$ perspektif projeksiyon genellikle bir pinhole kamera modeli olarak adlandırılır. Odak uzaklığı en çok vurgulanan dahili kamera geometri parametresi olmasına rağmen daha karmaşık parametrelendirmeler 

MERKEZI ÖRNE $\breve{I}$

mevcuttur. Aslında, gerçek kameraların diğer birçok iç geometri değişkenleri vardır. Daha eksiksiz bir kamera parametreleştirmesi Denklem 2'de verilmiştir [26, 27].

$$
\left(\begin{array}{l}
u \\
v
\end{array}\right)=K\left(\begin{array}{l}
X \\
Y \\
Z
\end{array}\right) \quad K=\left(\begin{array}{ccc}
s_{x} & s_{\theta} & u_{0} \\
0 & s_{y} & v_{0}
\end{array}\right)
$$

Burada, K matrisi, x ve y eksenleri boyunca görüntü düzleminin ölçeklemeleri olan $s_{x}$ ve $s_{y}$ 'yi içerir. Ayrica X ve y eksenleri ve görüntü düzlemindeki asıl noktaların koordinatları $\left(u_{0} ; v_{0}\right)$ arasındaki eğikliği belirtmektedir. $\mathrm{K}$ matrisinde özetlenen doğrusal etkilere ek olarak, lens distorsiyonu gibi diğer lineer olmayan ve ikinci dereceden etkiler de vardır. Genel anlamda, K matrisindeki bu ikinci dereceden etkiler ve hatta değişkenler standart düzeltici eğriltme yöntemleri aracıllğıyla düzeltilebilir ve yaklaşıklaştırılabilir [26].

Pek çok doğrusal olmayan çerçeve Horn tarafindan önerilen klasik göreceli oryantasyon problemi ile ilgili olabilir [27]. Bu yöntem perspektif projeksiyonlu kamera modeline sahip iki çerçeveli bir tekniktir. Yapı ve hareket (ancak kamera iç geometrisi yok), doğrusal olmayan bir maliyet fonksiyonu minimize edilerek düzeltilebilir [26].

Yöntem, epipolar ayrıntıları olmayan Şekil 6'dakine benzer bir düzenle başlar. Buna ek olarak, odak uzaklığı fnin verildiği varsayılmıştır. P noktasının aslında iki farklı koordinat sisteminde (her projeksiyon merkezi için bir tane) bilinmeyen üç boyutlu koordinatların $P_{1}$ ve $P_{2}$ olarak temsil edildiğini varsayalım. Bu 3B koordinatlar doğrudan Denklem 3'de olduğu gibi perspektif projeksiyon aracıllğıyla 2B projeksiyonlarla $\left(u_{1} ; v_{1}\right)$ ve $\left(u_{2} ; v_{2}\right)$ ilişkilidir [26].

$$
X_{1}=u_{1} \frac{Z_{1}}{f} \quad Y_{1}=v_{1} \frac{Z_{1}}{f}
$$

P'nin bir görüntü düzlemindeki izdüşümü, diğer koordinat sisteminde 3B noktanın dönüklüğü ve ötelemesi olarak tanımlanabilir. Böylece, 1 nolu projeksiyon merkezi içindeki 3B nokta 2 nolu projeksiyon merkezi içindeki 3B noktadan Denklem 4'teki gibi hesaplanabilir. Burada $\mathrm{R}$ dönüklüğ̈̈ ve t ötelemesi iki kamera arasındaki göreli 3B hareketi tanımlamaktadır [26].

$$
\left(\begin{array}{l}
X_{2} \\
Y_{2} \\
Z_{2}
\end{array}\right)=R\left(\begin{array}{l}
X_{1} \\
Y_{1} \\
Z_{1}
\end{array}\right)+t \quad\left(\begin{array}{c}
u_{2} Z_{2} / Z_{1} \\
v_{2} Z_{2} / Z_{1} \\
f Z_{2} / Z_{1}
\end{array}\right)=R\left(\begin{array}{c}
u_{1} \\
v_{1} \\
f
\end{array}\right)+t \frac{f}{Z_{1}}
$$

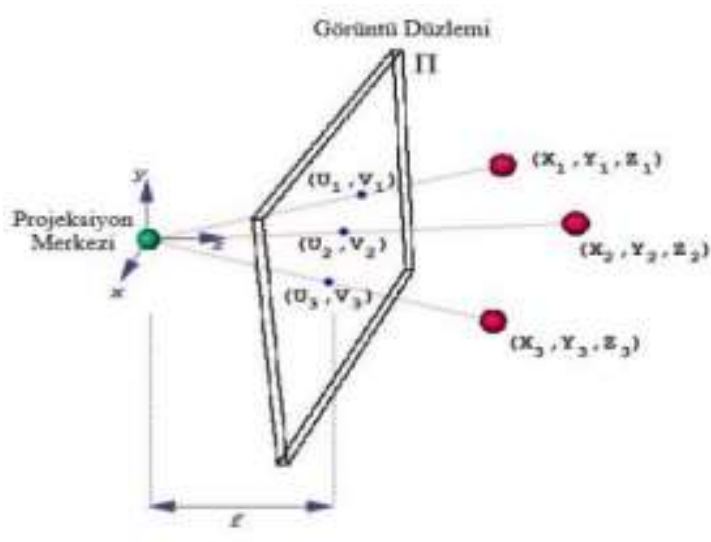

Şekil 5. Perspektif Projeksiyon [26]

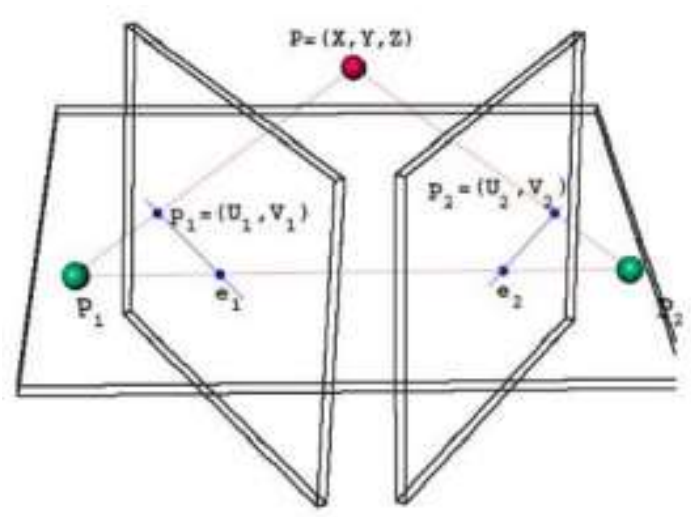

Şekil 6. Epipolar Geometri [26] 


\section{E. TERCAN}

Her biri birbirine karşılık gelen nokta çifti, sistemi iki bilinmeyenli ( $z_{1}$ ve $z_{2}$ ) üç eşitlik ile çözmektedir. Sistem, rastgele bir ölçeklendirme yapabilir ve benzersiz bir çözümü zorlamak için bir normalite kısıtı öteleme için uygulanmaktadır. Buna ek olarak, dönme matrisi üzerinde ortonormalite kısıtlamaları vardır (yalnızca 3 gerçek serbestlik derecesine sahiptir). Böylece, göreli 3B hareketi için 5 bilinmeyen, 5 nokta eşleşmeleri kullanılarak çözülebilir. Ancak, doğruluk için daha fazla nokta içeren en küçük kareler modeli tercih edilir. Çözüm, yinelemeli doğrusal olmayan optimizasyonu kullanarak hatayı en aza indirir. Bu süreçte $Z_{1}$ ve $Z_{2}$ değerleri, birbirine karşılık gelen her bir nokta için çözülür ve 3B yapı düzeltilir [26].

$\mathrm{Bu}$ çalışmada, İHA sistemi ile alınan görüntülerin işlenmesi, SFM algoritmasını kullanan, Rus üretici Agisoft LLC tarafından geliştirilen PhotoScan yazılımı kullanılarak gerçekleştirilmiştir. PhotoScan, SFM algoritmasını uygulayarak görüntülerden 3B modelin geriçatımına olanak sağlamaktadır. PhotoScan ile görüntülerin işlenmesi sürecinde İHA ile elde edilen fotoğraflar yazılıma yüklenmekte ve fotoğraflarda düzeltme yapılmaktadır. Fotoğrafların düzeltildiği bu aşamada PhotoScan her bir resim için kamera konum ve oryantasyonlarını hesaplamakta ve nokta bulutu modelini üretmektedir. Yoğun nokta bulutu üretiminden sonra 3B poligonal model (mesh) üretimi ve doku haritalama (texture) gerçekleştirilmektedir. Sonuç olarak renklendirilmiş nokta bulutu, sayısal yükseklik modeli ya da bir ortofoto üretilmektedir [29].

\subsubsection{Filtreleme Süreci}

$\mathrm{Bu}$ çalışmada, çıplak yeryüzü ile ağaç, bina, elektrik direği gibi detaylar Cloth Simulation Filter (CSF) algoritması ile birbirinden ayıklanmıştır. CSF algoritması ile çıplak yeryüzü ve detaylar ayrıştırıldıktan sonra elde edilen çıplak yeryüzüne Gaussian tabanlı filtreleme uygulanmıştır.

\subsubsection{CSF Algoritması}

Geniş ölçüm sahalarında üç boyutlu nokta bulutu ve sayısal arazi modeli elde etmek için insansız hava aracı sistemleri son dönemlerde yaygın olarak kullanılmaktadır. Sayısal arazi modeli üretimi için nokta bulutlarını zeminden ve zeminden olmayan ölçümlere ayırmak önemli bir aşamadır. Çoğu filtreleme algoritması yüksek doğruluk elde etmek için bazı karmaşık parametrelerin ayarlanmasına gereksinim duymaktadır [30].

Nokta bulutlarından zemin noktalarını çıkarmak için geliştirilen Cloth Simulation Filtering (CSF) algoritmasının genel görünüşü Şekil 7'de verilmiştir. Bu algoritmada ilk olarak, orijinal nokta bulutu ters döndürülür ve sonra bir örtü (cloth) üst taraftan ters çevrilmiş yüzeye düşer. Örtünün düğümleri ile ona karş1lık gelen nokta bulutları arasındaki etkileşim analiz edilerek, örtünün son şekli belirlenebilir ve bu örtü orijinal noktaları zemin ve zemin olmayan bölümlere sınıflamak için bir referans olarak kullanılabilir [30].

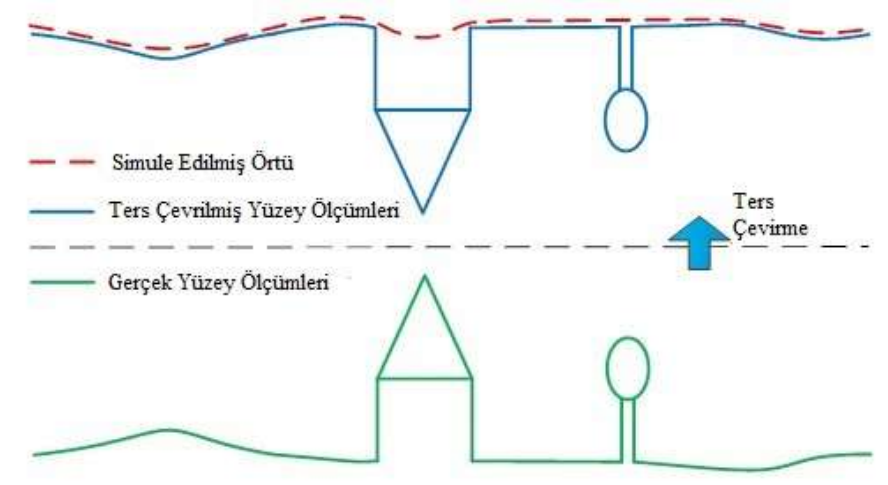

Şekil 7. CSF Algoritmasına genel bakış [30]

CSF algoritmasının temel uygulama aşamaları değerlendirilirse öncelikle, örtü parçacıkları ve nokta bulutları aynı yatay düzlemde projelendirilir ve bu 2B düzlemdeki her örtü parçacığı için en yakın karşılık gelen nokta bulunur. Karşılık gelen noktanın yükseklik değerini kaydetmek için bir kesişme yükseklik değeri tanımlanmıştır. $\mathrm{Bu}$ değer, bir parçacığın erişebileceği en düşük konumu temsil eder ve parçacık bu değer tarafından tanımlanan en düşük konuma ulaştığında artık ilerleyemez. Her iterasyonda, bir parçacı̆̆ın mevcut yükseklik değeri kesişme yükseklik değeri ile karşılaştırılır. Mevcut yükseklik değeri, kesişme yükseklik değerinden düşükse, parçacık kesişme yükseklik konumuna geri getirilir ve parçacık taşınamaz hale getirilir. Simülasyondan sonra gerçek 

MERKEZI ÖRNE $\breve{I}$

arazinin bir taslağı elde edilir ve orijinal nokta bulutu ile simüle parçacıklar arasındaki uzaklıklar buluttan buluta uzaklık hesaplama algoritması [31] kullanılarak hesaplanır. Bir eşik değerden daha düşük mesafelerde olan noktalar çıplak toprak olarak sınıflandırılırken, geri kalan noktalar nesneler olarak sınıflandırılır [30].

Zemin noktalarının tanımlanmasına yardımcı olmak için bu algoritmada mesafe eşiği ve yükseklik farkı olmak üzere iki eşik parametresi kullanılmaktadır. Mesafe eşiği, noktalar ve simüle edilmiş yüzey arasındaki mesafelere dayalı olarak nokta bulutlarını, zemin ve zemin olmayan parçalara sınıflandırmak için bir eşiktir. Başka bir eşik parametresi, hareketli bir parçacığın zemine taşınması gerekip gerekmediğini belirlemek için, post-processing esnasında kullanılan yükseklik farkıdır. Maksimum iterasyonlar arazi simülasyonunun maksimum iterasyon sürelerini ifade etmektedir [30].

\subsubsection{Gaussian Filtreleme}

Bilgisayarların hesaplama becerilerinin gelişmesi yüksek hesaplama yükü gerektiren Gaussian Filtrelerin nokta bulutlarına uygulanmasını daha kolay hale getirmiştir. Gaussian filtreler, filtreleme sonucunu elde etmek için Gaussian fonksiyonlarından faydalanan alçak geçirgenli istatistiksel filtrelerdir. Gaussian filtreler veride detay kaybına sebep olmasına rağmen hızlı ve basit bir yapıya sahiptir. Bu sebeple de yaygın olarak kullanılmaktadır. Gaussian filtrenin neden olduğu veri kaybını sınırlamak için geliştirilmiş Bilateral filtre gibi gaussian türevi filtreler de bulunmaktadır. Bir $f_{(x, y, z)}$ verteksinin kendine en yakın komşu nokta kümesi $k$ olmak üzere; bu verteksle en yakın komşu noktaları arasındaki öklid uzaklıkları Denklem (5) kullanılarak hesaplanır.

$$
d=\operatorname{dist}\left(f_{(x, y, z)}, k\right)
$$

Denklem (5) kullanılarak hesaplanan uzaklık değerleri, Denklem (6) kullanılarak Gaussian ağırlık değerlerine dönüştürülür.

$$
G_{\sigma}(p)=\frac{1}{2 \pi \sigma^{2}} \mathrm{e}^{-\frac{d^{2}}{2 \sigma^{2}}}
$$

Denklem (6)'da $\sigma$ değeri değiştikçe elde edilen katı model değişir. $\sigma$ değerini belirlemek uzmanlık ve tecrübe istese de, görsel-istatistiksel testler uygulanarak uygun değer kestirilebilir.

Denklem (6) kullanılarak elde edilen ağıllık değerleri, $k$ vertekslerinin konumlarını kaynaştırmak amacıyla kullanıldığında ilgili verteks filtrelenmiş olur. Bu durum Denklem (7) kullanılarak ifade edilmiştir.

$$
W_{f_{(x, y, z)}}=G_{\sigma}(p) k
$$

3D Gaussian filtrelemelerde daha optimum sonuç elde etmek için Denklem (7)'de gösterilen ifade, normal dağılıma açılabilir güven aralığı değiştirilerek daha iyi sonuçlar alınabilir [32-34].

\section{BULGULAR VE TARTIŞMA}

Agisoft PhotoScan yazılımında, georeferanslama ve blok dengeleme sonucunda GNSS cihazı ile CORS-RTK yöntemiyle ölçülmüş yer kontrol noktalarındaki karesel ortalama hatalar Tablo 2'de verilmiştir.

$\mathrm{Bu}$ çalı̧̧mada, yer kontrol noktalarının uçuşlar sonucunda elde edilen fotoğraflarda işaretlenmesiyle fotoğraf eşleme işlemi yapıldıktan sonra $15.424,417$ adet renklendirilmiş 3B nokta bulutu üretilmiştir. Çalışma koridorunun 140 metre uçuş yüksekliğinde $4,9 \mathrm{~cm}$ mekânsal çözünürlüklü ortofoto görüntüsü (Şekil 12, Şekil 15) üretilmiştir.

İHA yöntemi ile elde edilen nokta bulutuna CSF ve Gaussian filtreleme yöntemleri uygulanmıştır. Çıplak yeryüzü ile ağaç, bina, elektrik direği gibi detaylar Cloth Simulation Filter (CSF) algoritması ile birbirinden ayıklanmıştır. Sınıflandırma eşik değeri $0,5 \mathrm{~m}$, yükseklik farkı eşik değeri $0,3 \mathrm{~m}$ olarak alınmıştır. İterasyon sayısı ise 500 alınmıştır. Bu çalışmada kullanılan CSF algoritmasının nokta bulutlarına uygulanmasında Cloud Compare [35] yazılımı kullanılmış olup ayıklanmış görüntüler Şekil 8 ve Şekil 9'da verilmiştir. 


\section{E. TERCAN}

Tablo 2. Yer kontrol noktalarında gerçekleşen hatalar

\begin{tabular}{|c|c|c|c|}
\hline \multirow{2}{*}{ Nokta No } & \multicolumn{3}{|c|}{ Hata Miktarı (m) } \\
\cline { 2 - 4 } & $\Delta \mathbf{y}, \Delta \mathbf{x}$ & $\Delta \mathbf{z}$ & $\Delta \mathbf{y x z}$ \\
\hline P.1 & 0,0236 & $-0,0025$ & 0,0238 \\
\hline P.2 & 0,0612 & 0,0025 & 0,0613 \\
\hline P.3 & 0,0578 & 0,0001 & 0,0578 \\
\hline P.4 & 0,0300 & $-0,0013$ & 0,0300 \\
\hline P.5 & 0,0216 & 0,0002 & 0,0216 \\
\hline P.6 & 0,0338 & $-0,0224$ & 0,0338 \\
\hline P.7 & 0,0201 & 0,0015 & 0,0202 \\
\hline RMS (m) & 0,0388 & 0,0018 & 0,0389 \\
\hline
\end{tabular}

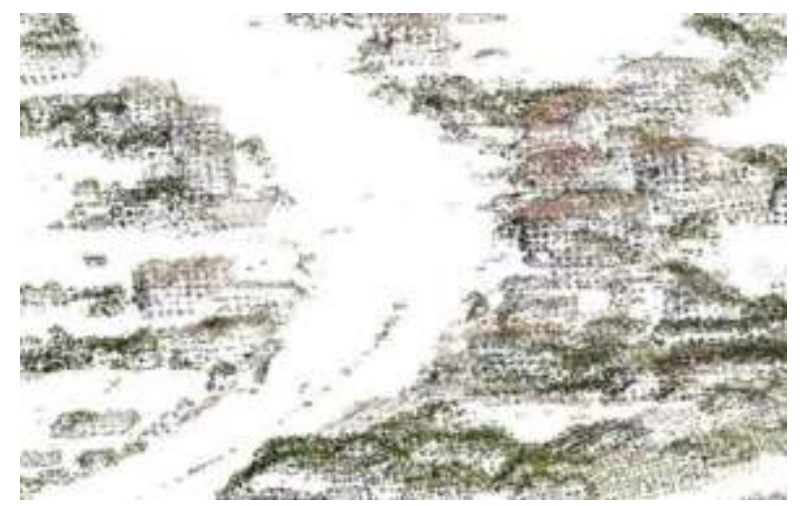

Şekil 8. Çıplak yeryüzü ve detayların ayrıştırılması sonrasında çıplak yeryüzü

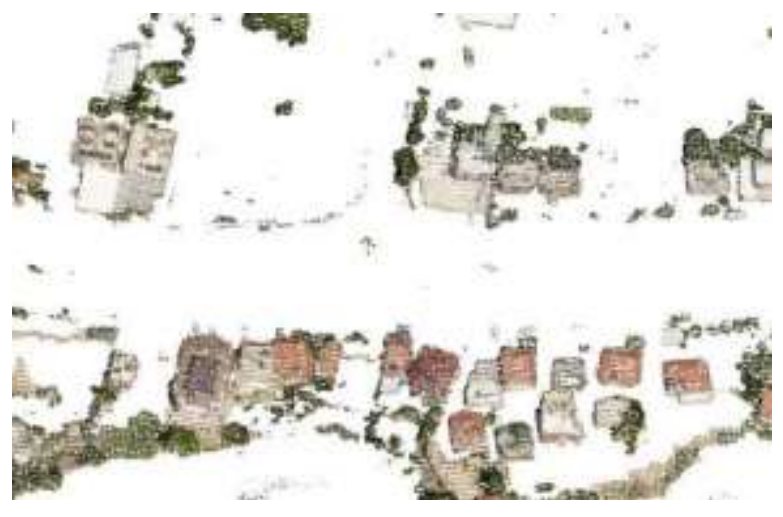

Şekil 9. Çıplak yeryüzü ve detayların ayrıştırılması sonrasında detay bilgileri

Çıplak yeryüzüne Gaussian tabanlı filtreleme uygulanması sonucunda elde edilen görüntüler Şekil 10 ve Şekil 11 'de verilmiştir. Bu çalışmada yapılan analizler sonucunda optimum $\sigma$ değeri deneysel olarak 0,4 mm olarak seçilmiştir.

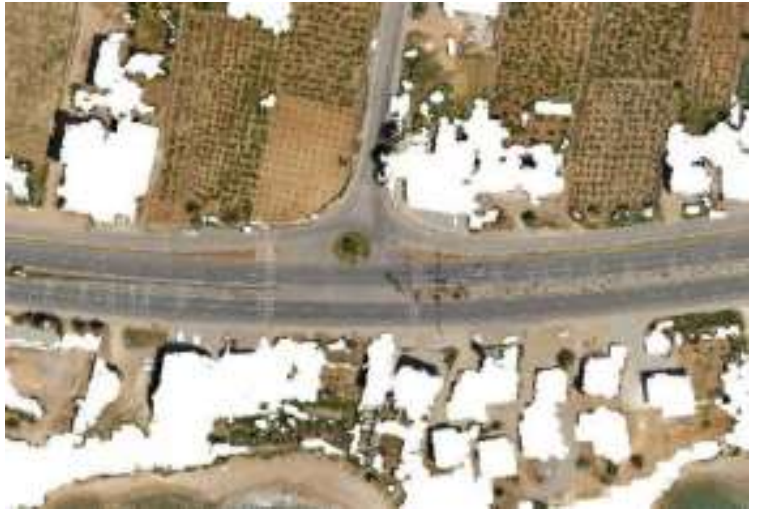

Şekil 10. Gaussian tabanlı filtreleme sonucu elde edilen nokta bulutu

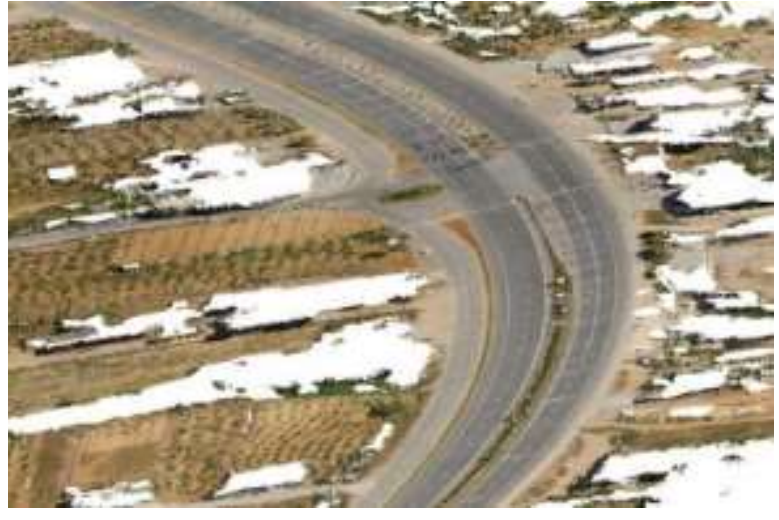

Şekil 11. Gaussian tabanlı filtreleme sonucu elde edilen nokta bulutu

Filtreleme sonucundaki nokta bulutu dosyası ve hat dosyası kullanılarak Micro Station v8i Inroads yazılımında sayısal arazi modeli üretilmiştir.

Doğruluk analizlerinin yapılabilmesi için aynı test karayolu koridorunda yersel yöntem ile detaylar GNSSRTK ölçü yöntemiyle 20 epok boyunca ölçülmüş ve test karayolu koridorunun Micro Station v8i Inroads yazılımında sayısal arazi modeli üretilmiştir.

İki yöntemin karşılaştırılması süreci Micro Station v8i Inroads yazılımında gerçekleştirilmiştir. İki yöntemden elde edilen sayısal arazi modelleri, yol platformu ve ham araziyi kapsayacak şekilde 50 metrelik bir kesitte 4 
farklı yerde karşılaştırılmış (Şekil 12 ve Şekil 15), karşılaştırma sonuçları Şekil 13,14,16,17'de profil olarak gösterilmiştir.

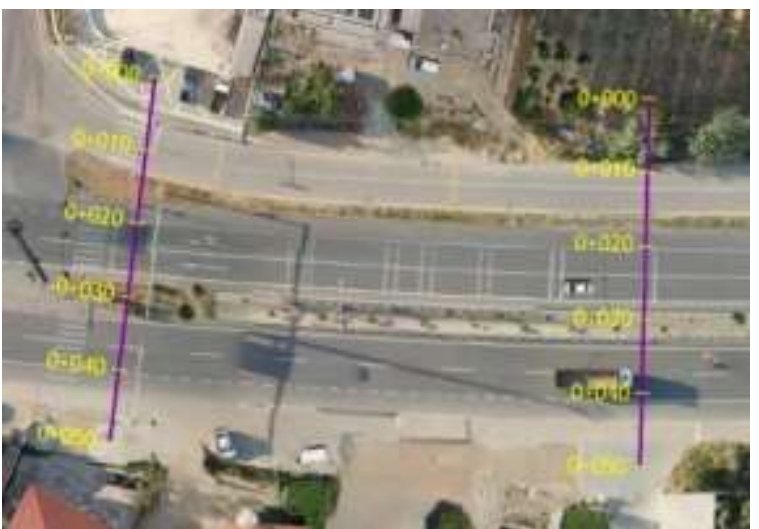

Şekil 12. Yol ekseninden alınan kesitlere ait ortofoto görüntü (Sol: 1. kesit ve sağ: 2. kesit)

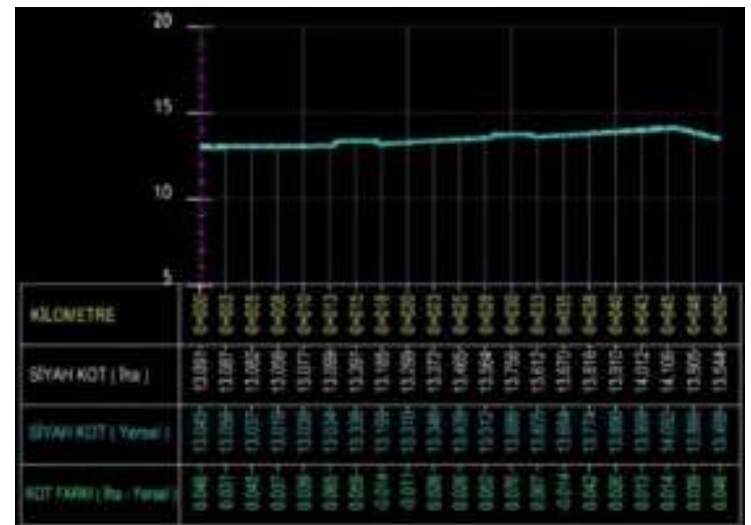

Şekil 13. Yol ekseninden alınan 1. kesit

Şekil 13 ve Şekil 14 'te verilen kesitler ve Şekil 12 incelendiğinde iki yöntemden elde edilen sayısal arazi modelleri örtüş̧mektedir. Sert satıhlı BSK kaplamalı yüzeylerde (Km: 0+016-0+028 ve Km: 0+032-0+044) 0,7$5,2 \mathrm{~cm}$ aralığında kot farkı belirlenmiştir. Şekil 12 (Sol:1 kesit) ve Şekil 13'de görüldüğü gibi Km:0+013-0+16 ve $\mathrm{Km}: 0+028-0+032$ 'de orta refüjde 5,2-6,5 $\mathrm{cm}$ aralığında kot farkı belirlenmiş olup her iki yöntemde de tretuarlı ve toprak dolgulu orta refüj kesiti belirgin bir şekilde çıkartılmıştır. Şekil 12 (Sağ: 2.Kesit) ve Şekil 14 'te görüldüğ̈̈ gibi orta refüjde trapez kesitli kanalın olduğu kesimde (Km: 0+029-0+033) 1,2-2,6 cm aralığında kot farkı tespit edilmiş olup her iki yöntemde de orta refüjde bulunan trapez kesitli orta refüj kesiti belirgin bir şekilde çıkartılmıştır.

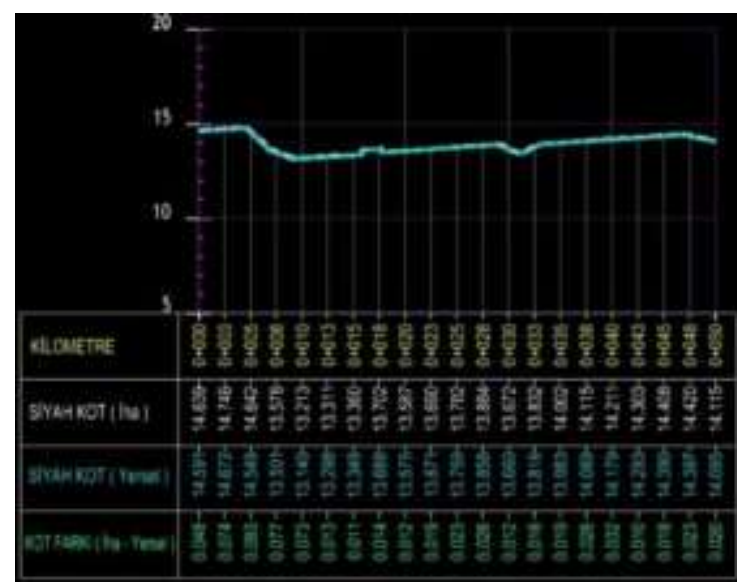

Şekil 14. Yol ekseninden alınan 2. kesit

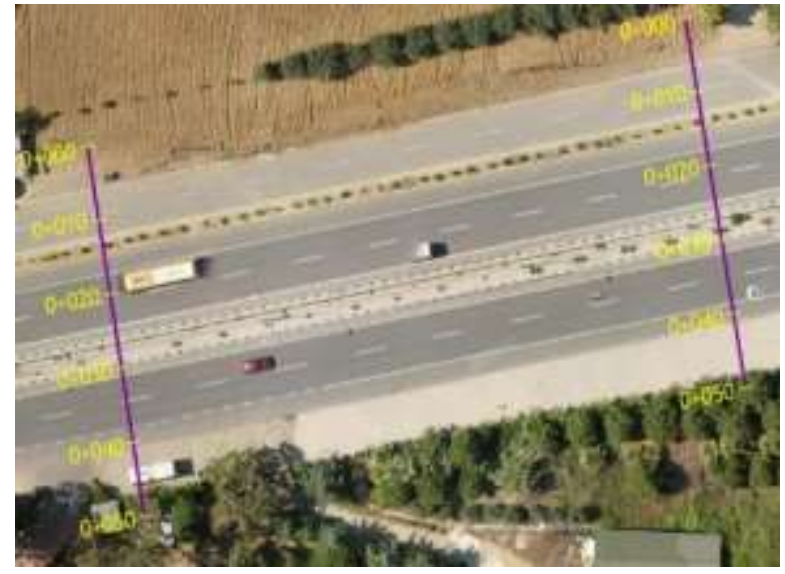

Şekil 15. Yol ekseninden alınan kesitlere ait ortofoto görüntü (sol: 3. kesit ve sağ: 4. kesit)

Şekil 16 ve Şekil 17 'de verilen kesitler ve Şekil 15 incelendiğinde iki yöntemden elde edilen sayısal arazi modelleri örtüşmektedir. Sert satıhlı BSK kaplamalı yüzeylerde (Km: 0+014-0+026 ve Km: 0+031-0+043) 1,4$4,9 \mathrm{~cm}$ aralığında kot farkı belirlenmiştir. Orta refüjde trapez kesitli kanalın olduğu kesimde (Km:0+026-0+31) 1,7-5,2 cm aralığında kot farkı belirlenmiş olup her iki yöntemde de bu kesit belirgin bir şekilde çıkarılmıştır. Km: 0+047-Km:0+050'de sık ve gür bitki örtüsünün olmadığı hafif çalılık olan bölgede 2,5-7,9 cm aralığında kot farkı belirlenmiştir.

Sayısal arazi modellerinden yol kesitlerindeki noktalarda yükseklik bilgisinde (z) oluşan toplam 84 kesit noktası için karesel ortalama hata (İHA yönteminden elde edilen ölçü değerinden yersel yöntemle elde edilen ölçü değeri düşülmek suretiyle) Denklem 8 ile hesaplanmıştır. Genellikle sert satıhlı zeminlerden oluşan yol platformunda hesaplanan düşey doğruluk $3,96 \mathrm{~cm}$ olarak belirlenmiştir. 


\section{E. TERCAN}

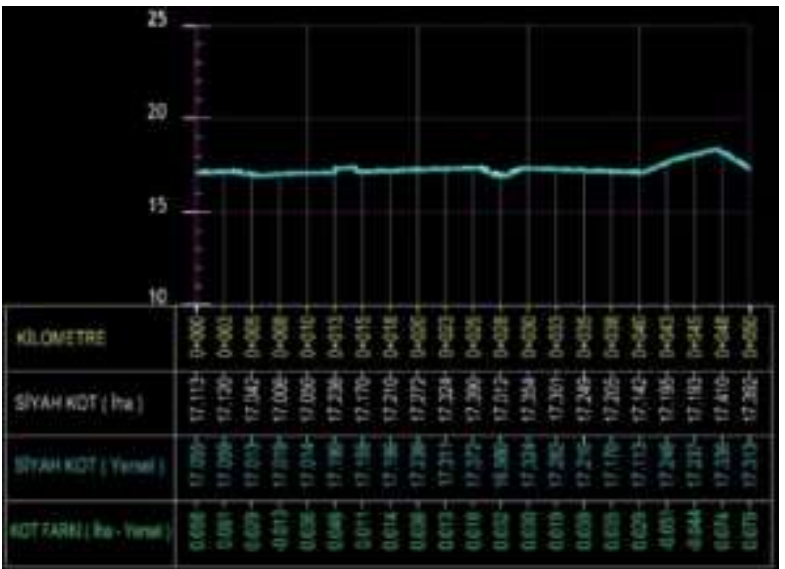

Şekil 16. Yol ekseninden alınan 3. kesit

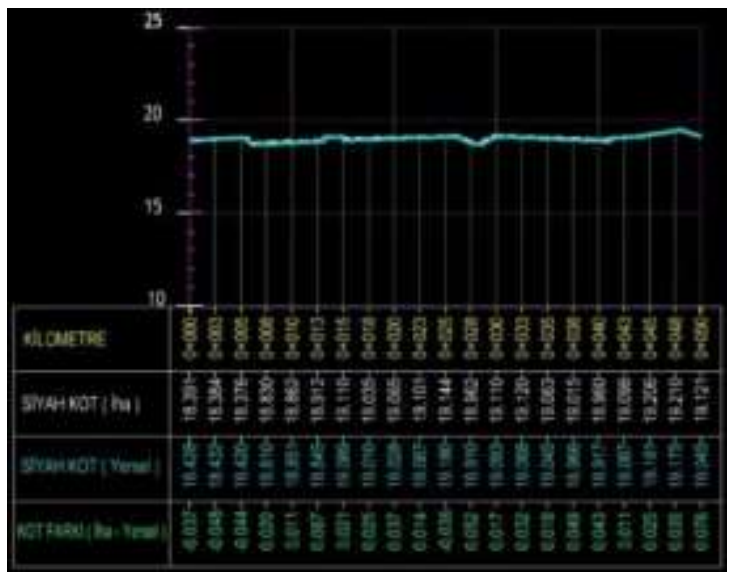

Şekil 17. Yol ekseninden alınan 4. kesit

$$
m_{z}=\sqrt{\frac{[\varepsilon \varepsilon]}{n}}
$$

İHA yönteminden elde edilen aynı noktalarda aplikasyon yapılmak suretiyle toprak zeminlerde doğruluk analizinin yapılması için 30 adet kontrol noktasında 20 epok GNSS-RTK ölçü yöntemiyle ölçüm yapılmıştır (Şekil 18). Yükseklik bilgisinde (z) oluşan karesel ortalama hata, aynı noktadaki İHA yönteminden elde edilen değerden GNSS-RTK ölçü yöntemiyle elde edilen değer düşülerek Denklem (8) ile hesaplanmıştır. Hesaplanan düşey doğruluk $7,32 \mathrm{~cm}$ olarak belirlenmiştir.

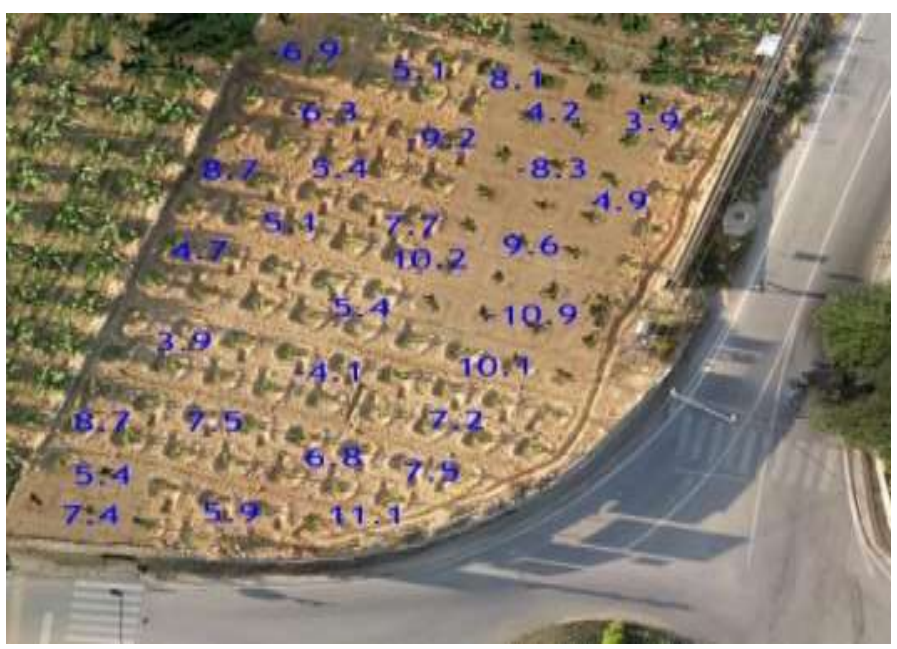

Şekil 18. Toprak zemin ölçü farkları $(\mathrm{cm})$

\section{SONUÇLAR}

Maliyet ve zaman rekabetçi alternatifler sunan ve satın alma bedelleri düşüş eğiliminde olan İHA fotogrametri sistemleri, birçok farklı alanda uygulama olanağına kavuşmuştur. Düşük maliyetle yüksek doğruluk ve hassasiyette 3B veri elde edilmesinden dolayı İHA sistemleri, karayolu ölçüm koridorlarında yersel ölçme ve klasik fotogrametri yöntemlerine ciddi bir alternatif olmuştur.

$\mathrm{Bu}$ çalışmada, SFM algoritması kullanılarak İHA sistemi ile elde edilen görüntüler işlenmiş ve karayolu koridorunun 4,9 cm mekânsal çözünürlüklü ortofoto görüntüsü elde edilmiştir. İHA sisteminin doğruluğu geleneksel yersel yöntem ile test edilmiş, İHA yönteminin sert satıhlı zeminlerde 3,96 cm, toprak zeminlerde $7,32 \mathrm{~cm}$ düşey doğrulukla 3B veri üretilebileceği ve iki yöntemin yol platformunun kesit olarak çıkartılmasında yakın sonuçların elde edilebileceği belirlenmiştir. Elde edilen sonuçlar, İHA sistemlerinin, topografik olarak düz 

MERKEZI ÖRNE $\breve{I}$

arazi yapılı karayolu koridorlarında ve bitki örtüsü az ya da hiç olmayan açı alanlarda ortofoto görüntü, sayısal yükseklik ve arazi modeli üretiminde kullanılacağını göstermektedir.

$\mathrm{Bu}$ çalışmada ele alınan, karayolu şehir geçişi gibi ölçüm koridorlarında İHA sistemi ile ortofoto görüntü ve sayısal arazi modeli üretiminin yüksek doğruluk ve hassasiyette yapılması gelecekte yapılacak çalışmalara önemli bir zemin oluşturmasının yanı sıra 3B kent modellerinin İHA sistemleri ile düşük maliyetle elde edilmesine katkı sağlayacaktır.

Ülkemizde 1/1000 ölçekli hâlihazır harita üretim çalışmalarında genellikle geleneksel yersel yöntemler kullanılmakta, bu yöntemlerle trafiğin yoğun ve ölçülecek detayların fazla olduğu karayolu koridorlarında çok sayıda ve yeterli doğrulukta 3B veri edilmesi zaman, maliyet ve güvenlik açısından olumsuzluklara sahiptir. İHA sistemlerinin hızlı ve yoğun trafik akışı ve ölçülmesi gereken detayların fazla olduğu karayolu koridorlarında kullanılması ile zaman kaybı ve toplam maliyet azalacak, yüksek doğruluk ve hassasiyette 3B veri elde edilerek sayısal arazi modelleri daha doğru üretilecek, arazide detay ölçüm çalışmalarında özellikle yol ekseninde işçi çalıştırılmadığı için iş kazaları da azalacaktır. İHA fotogrametrik yöntemlerinin tüm avantajlarına rağmen fotogrametrik yöntemle yeterli doğrulukta ölçülmesi zor olan menfez, hendek, köprü, enerji iletim hattı-yol kesişimlerinde telin yoldan yüksekliğinin belirlenmesi gibi karayolu projeleri için önemli detayların daha doğru ve hassas çıarılması için İHA fotogrametri yönteminin yersel yöntem ile desteklenmesi gereklidir.

Uçuşların daha alçaktan yapılmasıyla daha küçük yer örnekleme aralıklı ve karesel ortalama hatalı veri seti elde edilebilir. Ancak sabit kanatlı insansız hava araçları kullanılarak çok alçak irtifalardan uçuş yapmanın uygun olmadığı koşullarda çok yüksek doğruluklu veri setine ihtiyaç duyulması halinde döner kanatlı insansız hava araçlarının kullanılması daha uygun olacaktır.

Özellikle yol projelerinin ilk planlama aşamalarında (istikşaf çalışması gibi) insansız hava araçlarının etkin olarak kullanılması uygun geçki araştırmalarına ciddi katkı sağlayacaktır.

Sayısal arazi modeli üretimi için nokta bulutlarını zeminden ve zeminden olmayan ölçümleri ayırmak önemli bir aşama olup sayısal arazi modeli üretimine geçilmeden İHA sistemleri ile elde edilen nokta bulutu verilerinde doğruluğun artııılması için filtreleme işlemlerinin yapılması önerilmektedir.

Ülkemizde İHA sistemlerinin karayolu ölçme uygulamalarına ait yönetmelik ve teknik şartnamelerinde herhangi bir madde bulunmamaktadır. İHA sistemlerinin, düz arazi yapılı, bitki örtüsünün az ya da hiç olmadığı karayolu koridorlarında ortofoto görüntü ve sayısal harita üretim sürecinde yersel yöntemlerle bütünleşik kullanılması için Karayolları Genel Müdürlüğü'nce Karayolları Yersel ve Fotogrametrik Harita İşlerine ait Teknik Şartnamesinde düzenleme yapılması önerilmektedir.

\section{KAYNAKLAR}

[1] KARKINLI, A.E., KESIKOĞLU, A., KESIKOĞLU, M.H., ATASEVER, U.H., ÖZKAN, C., BEŞDOK, E., "İnsansız Hava Araçları ile Sayısal Arazi Modeli Üretimi", Türkiye Ulusal Fotogrametri ve Uzaktan Algılama Birliği (TUFUAB)VIII. Sempozyumu, 21-23 Mayıs, Konya, Türkiye, 2015.

[2] EISENBEISS, H., SAUERBIER, M., "Investigation of UAV Systems and Flight Modes for Photogrammetric Applications", The Photogrammetric Record, 26(136), 400-421, 2011.

[3] VEGA, F.A., RAMIREZ, F.C., SAIZ, P.S., ROSUA, F.O., "Multi-temporal Imaging Using an Unmanned Aerial Vehicle for Monitoring a Sunflower Crop", Biosystems Engineering, 132, 19-27, 2015.

[4] YU, N., LI, L., SCHMITZ, N., TIAN, L.F., GREENBERG, J.A., DIERS, B.W., "Development of Methods to Improve Soybean Yield Estimation and Predict Plant Maturity with an Unmanned Aerial Vehicle Based Platform", Remote Sensing of Environment, 187, 91-101, 2016.

[5] MESSINGER, M., SILMAN, M., "Unmanned Aerial Vehicles for the Assessment and Monitoring of Environmental Contamination: An Example from Coal Ash Spills”, Environmental Pollution, 218, 889-894, 2016.

[6] CHIABRANDO, F., NEX, F., PIATTI, D., RINAUDO, F., "UAV and RPV Systems for Photogrammetric Surveys in Archaelogical Areas: Two Tests in the Piedmont Region (Italy)", Journal of Archaeological Science, 38, 697-710, 2011.

[7] HENDRICKX, M., GHEYLE, W., BONNE, J., BOURGEOIS, J., DE WULF, A., GOOSSENS, R., "The Use of Stereoscopic Images Taken from a Microdrone for the Documentation of Heritage - An Example from the Tuekta Burial Mounds in The Russian Altay”, Journal of Archaeological Science, 38, 2968-2978, 2011.

[8] THEMISTOCLEOUS, K., LYSANDROU, V., CUCA, B., AGAPIOU, A., HADJIMITSIS, D.G., "Exploring the Ancient Kourion City Site from the Air Using Unmanned Aerial Vehicles", International Journal of Heritage in the Digital Era, 4, 307-323, 2015. 


\section{E. TERCAN}

[9] RATHINAM, S., KIM, Z.W., SENGUPTA, R., "Vision-based Monitoring of Locally Linear Structures Using an Unmanned Aerial Vehicle”, First Journal Of Infrastructure Systems, 14 (1), 52-63, 2008.

[10] ZHANG, C., ELAKSHER, A., “An Unmanned Aerial Vehicle Based Imaging System for 3D Measurement of Unpaved Road Surface Distresses”, Computer-Aided Civil Infrastructure Engineering, 27 (2), 118-129, 2011.

[11] SIEBERT, S., TEIZER, J., "Mobile 3D Mapping for Surveying Earthwork Projects Using an Unmanned Aerial Vehicle (UAV) System", Automation in Construction, 41, 1-14, 2014.

[12] EISENBEISS, H., UAV Photogrammetry, Dissertation Institute of Geodesy and Photogrammetry, ETH Zurich, Switzerland. 2009.

[13] REMONDINO, F., BARAZZETTI, L., NEX, F., SCAIONI, M., SARAZZI, D., "UAV Photogrammetry for Mapping and 3D Modeling-Current Status and Future Perspectives", Proceedings of the International Conference on Unmanned Aerial Vehicle in Geomatics (UAV-g), Zurich, Switzerland, 2011.

[14] HUDZIETZ, B.P., SARIPALLI, S., "An Experimental Evaluation of 3D Terrain Mapping with an Autonomous Helicopter", Proceedings of the International Conference on Unmanned Aerial Vehicle in Geomatics (UAV-g), Zurich, Switzerland, 2011.

[15] BUlATOV, D., SOLBRIG, P., GROSS, H., WERNERUS, P., REPASI, E., HEIPKE, C., “Context-Based Urban Terrain Reconstruction from UAV-Videos for Geoinformation Applications", Proceedings of the International Conference on Unmanned Aerial Vehicle in Geomatics (UAV-g), Zurich, Switzerland, 2011.

[16] SEYLAN, C., SEMIZ, F., BİCAN, O.S., “ İnsansız Araçlarla Düzlemsel Olmayan Alanların Taranması”, Savunma Bilimleri Dergisi, 11 (1), 107-117, 2012.

[17] AKGÜL, M., YURTSEVEN, H., DEMİR, M., AKAY, A.E., GÜLCİ, S., ÖZTÜRK, T., “ İnsansız Hava Araçları ile Yüksek Hassasiyette Sayısal Yükseklik Modeli Üretimi ve Ormancılıkta Kullanım Olanakları", İstanbul Üniversitesi Orman Fakültesi Dergisi, 66 (1), 104-118, 2016.

[18] ÖZCAN, O., "İnsansız Hava Aracı ile Farklı Yüksekliklerden Üretilen Sayısal Yüzey Modellerinin (SYM) Doğruluk Analizi”, Mühendislik ve Yer Bilimleri Dergisi, 2 (1), 1-7, 2017.

[19] http://www.mavinci.de/pro-version/ (erișim tarihi: 20.03.2017)

[20] BEŞDOK, E., KASAP, B., "3D Nesne Modellemeye Yönelik Lazerli Bir Tarayıcı Sistemin Tasarımı ve Gerçekleştirilmesi”, Eleco, Elektrik - Elektronik - Bilgisayar Mühendisliği Sempozyumu ve Fuarı Bildirileri, Bursa, Türkiye, 2006.

[21] LOWE, D.G., "Distinctive Image Features from Scale-Invariant Keypoints", International Journal of Computer Vision, 60 (2), 91-110, 2004.

[22] SNAVELY, N., SEITZ, S.M., SZELISKI, R., "Modeling the World from Internet Photo Collections", International Journal of Computer Vision, 80 (2), 189-210, 2008.

[23] FURUKAWA, Y., CURLESS, B., SEITZ, S.M., SZELISKI, R., "Towards Internet-Scale Multi-View Stereo", IEEE Conference on Computer Vision and Pattern Recognition (CVPR), 1434-1441, San Fransisco, USA, 2010.

[24] FURUKAWA, Y., PONCE, J., “Accurate, Dense and Robust Multiview Stereopsis”, IEEE Transactions Pattern Analysis and Machine Intelligence, 32 (8), 1362-1376, 2010.

[25] BESL, P.J., MCKAY, N.D., “A Method for Registration of 3D Shapes”, IEEE Transactions On Pattern Analysis And Machine Intelligence, 14 (2), 239-256, 1992.

[26] JEBERA, T., AZARBAYEJANI, A., PENTLAND, A., “3D Structure From 2D Motion”, IEEE Signal Processing Magazine, 3D And Stereoscopic Visual Communication, 16 (3), 66-84, 1999.

[27] MOHR, R., TRIGSS, B., “ Projective Geometry for Image Analysis”, Technical report, International Society for Photogrammetry and Remote Sensing, Vienna Congress, WG III/2 Tutorial, 1996.

[28] HORN, B.K.P., “ Relative Orientation”, International Journal of Computer Vision, 4 (1), 59-78, 1990.

[29] http://www.agisoft.com/pdf/photoscan pro_1_3_en.pdf (erişim tarihi: 12.03.2017)

[30] ZHANG, W., QI, J., WAN, P., WANG, H., XIE, D., WANG, X., YAN, G., “An Easy-to-Use Airborne LiDAR Data Filtering Method Based on Cloth Simulation” Remote Sensing, 8 (6), 501, 2016.

[31] MONTAUT, G.D., Cloud Compare-Open Source Project; OpenSource Project: Grenoble, France, 2011.

[32] ADAMS, A., GELFAND, N., DOLSON, J., LEVOY, M., "Gaussian Kd-trees for Fast High-dimensional Filtering" ACM Transactions on Graphics (ToG), Proceedings of ACM SIGGRAPH, p.21, New York, USA, 2009.

[33] WIRJADI, O., BRUEL, T., "Approximate Separable 3D Anisotropic Gauss Filter", Image Processing (ICIP) IEEE International Conference on, pp. II-149, 2005.

[34] GÜNEN, M.A., "Nokta Bulutu Filtreleme Algoritmalarının Karşılaştırılması” Erciyes Üniversitesi, Fen Bilimleri Enstitüsü, Yüksek Lisans Tezi, 78s, Kayseri, 2017.

[35] http://www.danielgm.net/cc/ (erişim tarihi: 08.08.2017) 